\title{
Herbivore dunging and endozoochorous seed deposition in a Mediterranean dehesa
}

\author{
J.E. MALO, B. JIMÉNEZ, AND F. SUAREZ
}

Authors are ecologists, Departamento Interuniversitario de Ecología. Facultad de Ciencias. Universidad Autónoma de Madrid. E-28049 Madrid. Spain. Malo's is e-mail: je.malo@uam.es; and Departamento de Ecología. Facultad de Medicina Veterinaria y Zootecnia. Universidad Autónoma de Yucatán. Mérida, Yucatán. México.

\section{Abstract}

Spatial patterns of herbivore defecation within grazing systems are important as they directly affect pasture growth and composition. These effects are partially linked to seed dispersal in dung, a little studied process. This paper focuses on: (i) quantification of dung and seeds deposited by herbivores in a Mediterranean grazing system, and (ii) analysis of the spatial variability of dung and seeds deposited within and among plant communities. We carried out year-long monthly quantifications of the depositions of rabbit (Oryctolagus cuniculus), fallow deer (Dama dama), red deer (Cervus elaphus), and cow (Bos taurus) dung to 32 plots distributed in Quercus rotundifolia Lam. and Fraxinus angustifolia Vahl woodlands, mixed scrub, and Cistus ladanifer L. scrub. We also quantified the germinable seed content of dung. The results revealed differences $(p<0.05)$ in dung deposition, varying (i) among the 4 species, (ii) within species (except for the red deer) among plant communities, and (iii) within plant communities. An average of $735 \mathrm{seeds} / \mathrm{m}^{2}$ were returned to the soil via dung, with the highest numbers in open woodlands $\left(870-1,888 \mathrm{seeds} / \mathrm{m}^{2}\right)$ and the lowest numbers in scrubs $\left(83-315\right.$ seeds $\left./ \mathbf{m}^{2}\right)$. Cows dispersed the most seeds $(68 \%)$, followed by red deer $(20 \%)$, rabbits $(7 \%)$, and fallow deer $(5 \%)$. Spatial variability in deposition led to accumulations of up to several thousand seeds at points covered by the dung. The effect of seed input to the seed bank and on vegetation may be low at large and medium-sized spatial scales, but it can be very important at small scales and for colonization processes.

Key Words: spatial pattern, dispersal, dung, herbivores, endozoochory, Mediterranean pastures

Deposition and degradation of herbivore dung are key processes that alter soil characteristics, botanical composition, and productivity in grazing lands (McNaughton 1984, Georgiadis and McNaughton 1990, Malo and Suárez 1995a) but little information exists concerning spatial patterns of herbivore defecation (e.g. Putman et al. 1991). Seed dispersal via herbivore dung (endozoochory) is known to happen, but effects on vegetation dynamics are poorly defined (Janzen 1984) with the exception of dispersal

Catherine Levassor helped us to identify seedlings, and Laparanza S.A. gave us permission to work on its property, Castillo de Viñuelas. This study was partially funded by the research projects DGICYT PB 91-0020, CICYT AMB 96-1231, and by the AECI Program "Incorporación de Jóvenes Doctores a Universidades Mejicanas" (position nr. 43/98 to Juan E. Malo).

Manuscript accepted 18 Sep. 1999.

\section{Resumen}

Los patrones de defecación de los herbívoros en los sistemas pastorales son de gran importancia, dado que afectan a la composición y el crecimiento del pastizal, y sus efectos se encuentran parcialmente ligados a un proceso muy poco estudiado, la dispersión de semillas en los excrementos. El presente estudio se centra en: (i) la cuantificación de los excrementos y semillas defecados por los herbívoros en una dehesa de la Península Ibérica, y (ii) en el análisis de la variabilidad espacial de la deposición de excrementos y semillas entre formaciones vegetales y dentro de las mismas. A lo largo de un año cuantificamos mensualmente los excrementos de conejo (Oryctolagus cuniculus), gamo (Dama dama), ciervo (Cervus elaphus) y vaca (Bos taurus) depositados en 32 parcelas distribuidas en zonas adehesadas de Quercus rotundifolia Lam. y de Fraxinus angustifolia Vahl, en matorrales mixtos, y en jarales de Cistus ladanifer L. Paralelamente, cuantificamos el contenido de semillas germinables de los excrementos de los cuatro herbívoros. Los resultados mostraron diferencias significativas $(p<0,05)$ en la deposición de excremento (i) entre los 4 herbívoros, (ii) individualmente para cada animal (excepto el ciervo) entre las cuatro formaciones vegetales, $y$ (iii) dentro de cada una de éstas. Estimamos una deposición media para toda la finca de $735 \mathrm{semillas} / \mathrm{m}^{2}$, correspondiendo los valores más altos a los pastizales arbolados $(\mathbf{8 7 0}-1.880$ semillas $/ \mathrm{m}^{2}$ ) y los más bajos a los matorrales (83-315 semillas $/ \mathrm{m}^{2}$ ). La variabilidad de la deposición es muy grande, por lo que en los lugares ocupados por los excrementos se producen acumulaciones de miles de semillas. Las vacas son los principales dispersantes ( $68 \%$ de las semillas), seguidos de los ciervos $(20 \%)$, los conejos (7\%) y los gamos (5\%). El efecto de la defecación de semillas sobre el banco de semillas y la vegetación puede ser poco relevante a escalas espaciales grandes y medianas, pero a pequeña escala, y en los procesos de colonización vegetal, puede ser muy importante.

of woody legumes (Miller and Coe 1993) and attempts to use livestock to sow pasture species (Ocumpaugh et al. 1996). High seed densities were recorded in herbivore dung in the Mediterranean (Russi et al. 1992, Malo and Suárez 1995b) and Australia (Jones et al. 1991, Gardener et al. 1993) while much lower densities occurred in other areas (Collins and Uno 1985, Welch 1985). However, information is lacking on quantification of seeds dispersed endozoochorously by herbivores. Objectives of this research were (i) to quantify herbivore dung and seed input to soil in an extensive grazing system on the Iberian Peninsula, and (ii) to analyse the spatial patterns of dung and seed 
deposition at 3 spatial scales: among and within plant communities, and at the scale of individual depositions.

\section{Material and Methods}

\section{Study Area}

The field work was done on the Castillo de Viñuelas estate, a roughly 3,000 ha dehesa (open woodland) $20 \mathrm{~km}$ north of Madrid (Central Spain, $40^{\circ} 37^{\prime} \mathrm{N}, 3^{\circ} 38 \mathrm{~W}$, $670 \mathrm{~m}$ above sea level). The dehesa ranching system is based on multiple uses (grazing, firewood extraction, hunting, and ploughing) of vegetation complexes formed by open woodlands, scrubland, and wooded pasture. Although human management has changed the former balance of woodland, scrubland, and pasture areas, the dehesa systems are considered to be similar to those that have existed in Western Iberia since prehistoric times (Aschmann 1973).

The property lies on Tertiary sands resulting from the erosion of the nearby Sierra de Guadarrama in an area with a dry mesomediterranean climate, an annual rainfall of around $550 \mathrm{~mm}$ and a dry summer from June to mid-September. The potential vegetation of the area is sclerophyllous forest dominated by Holm oak (Quercus rotundifolia Lam.) mixed with different scrub communities and replaced on valley floors by stands of ash (Fraxinus angustifolia Vahl). Due to the traditional use of the estate, 4 main plant communities can now be distinguished (J.M. de Miguel, unpubl. manuscript): (i) pastures with ash on the valley floors (ash woodlands hereafter, $16 \%$ of the estate area), (ii) pastures with large Holm oaks on the upper terraces and in other more or less flat areas (oak woodlands, 26\%), (iii) mixed scrubland with Santolina ros marinifolia L. and Thymus zygis L. along with small Holm oaks and a few Gum cistus (Cistus ladanifer L.) on the slopes, ploughed up occasionally to open up pastures (mixed scrub, 22\%), and (iv) practically monospecific scrubland of Gum cistus with a few Holm oaks in the highest zones (Cistus scrub, 36\%).

The estate now has a grazing-hunting usage similar to the traditional one, with a herd of 400 free ranging cattle throughout the estate. The main wild herbivores are fallow deer (Dama dama, approximately 0.28 individuals/ha), red deer (Cervus ela phus, 0.14 individuals/ha) and rabbit (Oryctolagus cuniculus, 6-18 individuals/ha, J.E. Malo unpubl. data).

\section{Quantification of Endozoochory}

To ascertain the number of seeds deposited, we (i) measured the input of cow, red and fallow deer, and rabbit dung in each of the 4 main plant communities of the estate, and (ii) quantified the seed content of the dung of each of the 4 herbivores.

To quantify dung deposition by the 4 herbivores over a year, we chose a roughly $0.8 \mathrm{~km}^{2}$ section of the estate away from human influence where the 4 vegetation types were in close proximity. On 25 March 1991, we delineated 32 plots of 2 x $25 \mathrm{~m}$ ( 8 in each vegetation type) in the ash woodland, oak woodland, mixed scrubland, and Cistus scrub. Plots were marked by pegs along the maximum slope line, parallel to each other, and $15 \mathrm{~m}$ apart. At one corner of each plot we established a 1 $\mathrm{x} 1 \mathrm{~m}$ subplot defined by string pegged to the ground. After establishing the plots, we removed all dung of red deer, fallow deer, and cows. In addition, rabbit pellets were removed from each of the $1 \times 1 \mathrm{~m}$ subplots.

At monthly intervals, coinciding with dung collections for seed content analysis (see dates in Fig. 1) we measured the dung deposited in the 32 plots. For this purpose we collected all the red and fallow deer dung in each $2 \times 25 \mathrm{~m}$ plot and counted the number of dung groups containing more than 5 pellets (Rowland et al. 1984). We also counted and measured the diameter and mean depth of each cow pat in the plots. These pats were then removed from the plots to prevent double counting on subsequent visits. We also collected and counted the rabbit pellets deposited in the $1 \mathrm{x} 1 \mathrm{~m}$ subplots.
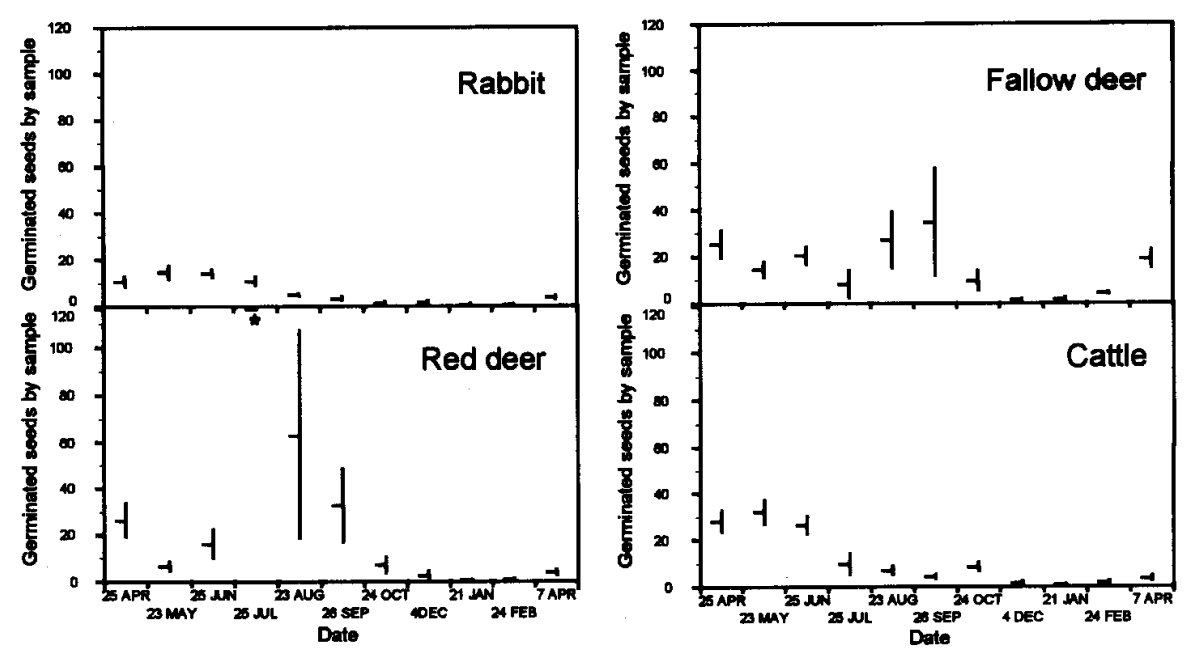

Fig. 1. Seed content (mean \pm standard error) of 3-g dung samples from 4 herbivore species over 1 year in the dehesa de Viñuelas. The red deer datum for 25-VII-1991 (249 \pm 124 , marked with a star) has been deleted to maintain the clarity of the representation.
The rabbit, fallow deer, and red deer dung was dried and stored in paper bags at room temperature until it was weighed to a precision of $\pm 0.01 \mathrm{~g}$ in autumn 1992 . The amount of cow dung was calculated from the diameter and average depth of the pats and the density of dry cow dung $\left(0.37 \mathrm{~g} / \mathrm{cm}^{3}\right.$, Malo and Suárez 1995c).

Viable seed content of the dung was determined by greenhouse germination. Between April 1991 and April 1992, coinciding with dung collections from the sampling plots (see dates in Fig. 1), we carried out 11 samplings of dung deposited by the 4 herbivores. Each collection consisted of 8 independent samples of fresh dung from each herbivore species, which were dried and stored at ambient temperature. In autumn of the collection year, $3 \mathrm{~g}$ from each sample was crushed gently and prepared for greenhouse germination in a mixture with $20 \mathrm{~g}$ of sterile sand over a bed of moist vermiculite. The samples were kept moist during the 2 October-June periods following collection (1991-92 and 1992-93 for the first 7 collections, and 1992-93 and 1993-94 for the rest). Given that in the field in this location, seeds germinate almost exclusively in autumn, this procedure simulated natural conditions. The proportion of ungerminated viable seeds in the samples after the 2 germination cycles was minimal: after keeping the samples of the first 7 collections in the greenhouse for another year (1993-94), only 49 germinations were found in comparison with 5,715 germinations during the first 2 years (less than $0.9 \%)$. For the purpose of simplicity, "seeds" refers hereafter to "seeds germinable during 2 seasons". 
In our interspecific comparisons of defecation, we used the data on dung weight per plot (in $\mathrm{g} / \mathrm{m}^{2}$ ). The data on the number of seeds deposited (per $\mathrm{m}^{2}$ or per defecation) were calculated from the average seed content in the dung on each collection date, and using individualized calculations of the defecations for each plot and date. In all calculations we assumed that the seed content in the herbivore dung was constant throughout plant communities. This assumption should be quite accurate for the 3 ungulates due to (i) the scope of their daily movements in the context of the size of the vegetation patches, permitting them to feed and defecate indiscriminately in all of them, and (ii) the length of time taken by the seeds to pass through the herbivores' digestive tracts, estimated to be between 2 and 6 days (Yamada and Kawaguchi 1972, Courtney 1973). On the other hand, the much smaller home range of rabbits might have resulted in overrating the dispersal role of rabbit dung in scrubs, although, as discussed below, this bias had no significant effect on the main conclusions.

The data were analysed using the SYSTAT programme using standard non-parametric procedures due to the lack of normality in the data sets. Due to the lack of precision of the non-parametric multifactorial analyses (Seaman et al. 1994), the comparisons between herbivores, plant communities, and plots in each community were done sequentially. The values obtained for $\mathrm{p}$ in each of the analyses are shown in tables 1-4, but to ensure that these probabilities satisfy the requirements for multiple inferences on data sets, the level of statistical significance taken as the base $(p<0.05)$ was corrected using the sequential procedure proposed by Rice (1989). Corrected values of the level of statistical significance are shown in each table.

\section{Results}

\section{Dung Deposition}

The total amount of dung deposited in the 32 sampling plots differed $(p<0.05)$ among the 4 herbivores (Table 1), ranging from a maximum for cows and rabbits $\left(17-21 \mathrm{~g} \mathrm{dung} / \mathrm{m}^{2}\right)$ to a minimum for the red deer and fallow deer (4-6 g dung $\left./ \mathrm{m}^{2}\right)$. There were also differences in amount of dung deposited among the plant communities by all herbivores except for red deer (Kruskal Wallis test; $\mathrm{p}<0.05$; Table 2). Cows and fallow deer had proportionally the lowest defecation rates in both scrub types (especially Cistus scrub). The

Table 1. Amount of dung ( $\mathrm{g}$ dry weight $/ \mathrm{m}^{2}$ ) deposited by 4 herbivore species in 32 permanent plots in a Mediterranean grazing system during one year ${ }^{\mathrm{a}}$.

\begin{tabular}{cccccccc}
\hline \hline & \multicolumn{4}{c}{ Herbivore species } & & \multicolumn{2}{c}{ Friedman test } \\
\cline { 2 - 3 } Dung & Rabbit & Fallow deer & Red deer & Cattle & & F & p \\
\hline & 21.6 & 4.3 & 5.7 & 17.1 & & 15.9 & $\mathbf{0 . 0 0 1}$ \\
& $25.6 \pm 3.3$ & $8.5 \pm 1.8$ & $7.8 \pm 1.2$ & $45.2 \pm 14.3$ & & \\
\hline
\end{tabular}

${ }^{a}$ Upper row: median values and result of their comparison using Friedman test for associated samples. Lower row: mean \pm s.e. for the data set. Level of statistical significance is $p<0.05$.

amount of rabbit dung collected in the mixed scrub was intermediate between the level in the 2 wooded pastures and appreciable, although lower, in the Cistus scrub. Finally, the defecation pattern of red deer among vegetation types was more homogeneus, though the difference among plant communities was close to statistical significance. As a result of these defecation patterns, Cistus scrub received the least herbivore dung of the 4 plant communities $(0-8$ $\mathrm{g} / \mathrm{m}^{2}$ of each species), followed, with the exception of the rabbit $\left(26 \mathrm{~g} / \mathrm{m}^{2}\right)$, by mixed scrub $\left(2-11 \mathrm{~g} / \mathrm{m}^{2}\right)$. In contrast, wooded pastures received much higher amounts: $7-45 \mathrm{~g} / \mathrm{m}^{22}$ in the ash woodlands and 9-38 $\mathrm{g} / \mathrm{m}^{2}$ in the Holm oak woodlands.

There were large differences in amount of dung deposited by each herbivore species among the plots within each plant community (Table 3 ). In some cases these differences corresponded to defecation patterns that were maintained among sample collection dates. Thus, there were differences $(p<0.05)$ in amounts of rabbit dung collected in the sub-plots of the 4 plant communities (Friedman test for repeated samples, Table 3). For fallow deer, differences $(p<0.05)$ occurred among samples from plots in ash and oak woodlands and for red deer only among plots from the oak woodlands. Cow dung showed no significant trends in spatial variation maintained over the whole sampling period in any of the plant communities.

Table 2. Mean dry dung weight (in $\mathrm{g} / \mathrm{m}^{2}$ ) deposited during one year by 4 herbivore species in plots in 4 plant communities in the dehesa of Viñuelas, a Mediterranean grazing system ${ }^{\mathrm{a}}$.

\begin{tabular}{|c|c|c|c|c|c|c|}
\hline & \multicolumn{3}{|c|}{ Deposited dung } & & \multicolumn{2}{|c|}{ Kruskal-Wallis } \\
\hline & Ash woodland & Oak woodland & Mixed scrub & Cistus scrub & $\mathrm{H}$ & $\mathrm{p}$ \\
\hline & 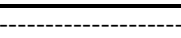 & $\left(\mathrm{g} / \mathrm{m}^{2}\right)$ & & ----------- & & \\
\hline Rabbit & 32.5 & 18.9 & 26.3 & 8.5 & 11.4 & $0.010^{b}$ \\
\hline Fallow deer & 7.1 & 18.4 & 2.3 & 0.9 & 24.0 & $<0.001^{b}$ \\
\hline Red deer & 7.0 & 9.5 & 5.6 & 2.9 & 9.3 & 0.025 \\
\hline Cattle & 44.5 & 37.9 & 11.0 & 0.0 & 15.8 & $0.001^{b}$ \\
\hline
\end{tabular}

${ }^{\mathrm{a}} \mathrm{N}=32$ for each animal species.

${ }^{\mathrm{b}}$ Probabilities below the corrected level of statistical significance according to Rice $(1989 ; \mathrm{p}<0.025)$.

\section{Dung Seed Content}

A total of 527 seeds germinated from the 88 rabbit dung samples (equivalent to 2.0 seeds/g of dry dung), 1,320 from fallow deer dung (5.0 seeds/g), 3,265 from red deer dung (12.4 seeds/g), and 982 from cow dung (3.7 seeds/g). The germinable seed content showed large seasonal variation in all 4 herbivore species, and the dispersal pattern also differed among species (Fig. 1). Thus, the highest seed concentration in dung was at the end of spring for rabbits and cows (4.7 and 10.7 seeds/g respectively), in mid-summer for red deer (83.0 seeds/g), and at the start of autumn for fallow deer (11.5 seeds/g). However, a few germinable seeds were found in dung at almost any time of the year.

\section{Seed Deposition}

Dung deposition and seed content data were used to calculate the number of seeds defecated by each animal species in each plant community and, using the proportion of each community on the estate, the average number deposited on the entire property (Table 4). Across communities and herbivores, this revealed an input of some 735 seeds $/ \mathrm{m}^{2}$ via dung. Cows were responsible for almost 500, red deer approximately 140 , rabbits 50 , and fallow deer 40 . There were also large differences among plant communities: nearly 1,900 seeds were deposited per $\mathrm{m}^{2}$ of oak woodland, less than 900 in ash woodlands, a little over 300 in mixed scrub and less than 100 in Cistus scrub. Differences in amount of 
Table 3. Range of variation in the amount of dung (in $\mathrm{g} / \mathrm{m}^{2}$ ) deposited by 4 herbivore species in 8 sample plots located in 4 plant communities in a Mediterranean grazing system, and results of Friedman test on repeated samples for the amount of dung deposited in them in 11 time periods.

\begin{tabular}{lcccc}
\hline \hline & \multicolumn{4}{c}{ Plant communities } \\
\cline { 2 - 5 } & Ash woodland & Oak woodland & Mixed scrub & Cistus scrub \\
\hline Rabbit $\left(\mathrm{g} \mathrm{m}^{-2}\right)$ & $17-65$ & $11-64$ & $4-57$ & $2-25$ \\
& $\mathrm{~F}=31.2$ & $\mathrm{~F}=33.8$ & $\mathrm{~F}=39.2$ & $\mathrm{~F}=42.5$ \\
& $\mathbf{p}<\mathbf{0 . 0 0 1}^{\mathbf{a}}$ & $\mathbf{p}<\mathbf{0 . 0 0 1}^{\mathbf{a}}$ & $\mathbf{p}<\mathbf{0 . 0 0 1}$ & $\mathbf{p}<\mathbf{0 . 0 0 1}$ \\
Fallow deer $\left(\mathrm{g} \mathrm{m}^{-2}\right)$ & $2-18$ & $10-38$ & $1-4$ & $0-4$ \\
& $\mathrm{~F}=28.7$ & $\mathrm{~F}=21.5$ & $\mathrm{~F}=8.6$ & $\mathrm{~F}=12.1$ \\
& $\mathbf{p}<\mathbf{0 . 0 0 1}^{\mathbf{a}}$ & $\mathbf{p}=\mathbf{0 . 0 0 3}^{\mathbf{a}}$ & $\mathrm{p}=0.280$ & $\mathrm{p}=0.098$ \\
Red deer $\left(\mathrm{g} \mathrm{m}^{-2}\right)$ & $4-15$ & $3-30$ & $3-14$ & $1-9$ \\
& $\mathrm{~F}=8.1$ & $\mathrm{~F}=21.6$ & $\mathrm{~F}=5.8$ & $\mathrm{~F}=7.9$ \\
& $\mathrm{p}=0.325$ & $\mathbf{p}=\mathbf{0 . 0 0 3}^{\mathbf{a}}$ & $\mathrm{p}=0.565$ & $\mathrm{p}=0.339$ \\
Cattle $\left(\mathrm{g} \mathrm{m}^{-2}\right)$ & $17-161$ & $0-375$ & $0-61$ & 0 \\
& $\mathrm{~F}=4.3$ & $\mathrm{~F}=6.1$ & $\mathrm{~F}=1.5$ & $\mathrm{~F}=0.0$ \\
& $\mathrm{p}=0.748$ & $\mathrm{p}=0.533$ & $\mathrm{p}=0.982$ & $\mathrm{p}=1.000$ \\
\hline
\end{tabular}

${ }^{a}$ Probabilities reaching the corrected level of statistical significance, according to Rice (1989, sequence: $p<0.0167 ; p$ $<0.0125 ; \mathrm{p}<0.01 ; \mathrm{p}<0.0083)$.

dung defecated among plots within each plant community (Table 3 ) are reflected in the wide range of seed numbers deposited in them (Table 4). In most cases, these differences were of an order of magnitude, and sometimes considerably larger.

Using the weight and number of droppings collected, we calculated the effect of seed input by the 4 herbivores at the very small spatial scale. The seed concentration in rabbit pellets varied from 0.01 seeds per pellet in January and February to 0.45 seeds per pellet in June (Fig. 2).

With each deposition (group of pellets identified during sampling), fallow deer defecated between 5 and 184 seeds (in December and September, respectively), and red deer between 3 (January) and 1,750 (June, Fig. 3). Finally, for each cow pat $\left(600 \mathrm{~cm}^{2}\right.$, Welch 1985) there was an input to the pasture ranging from 570 seeds in January to 9,900 in May (Fig. 4), the approximate equivalent of 1 to 16 seeds $/ \mathrm{cm}^{2}$ of area occupied by dung.

\section{Discussion}

Results show the high variability at different spatial scales in the defecation rates among the 4 herbivore species, and among and within different plant communities. To our knowledge, this is also the first presentation of data on endozoochorous seed deposition by all main herbivores sharing a pastoral system and in each of its plant communities.

\section{Dung Spatial Patterns}

Rabbits and cows deposited the largest amount of dung in the study area, between
4 and 5 times that of the red and fallow deer. The role of rabbits is especially noteworthy. Despite their small size, rabbits play a key role in this and many other aspects of the ecology of Mediterranean ecosystems within their natural range of distribution (Rogers et al. 1994) or where they have been introduced (Gibb and Williams 1994, Myers et al. 1994). This is also backed by the fact that red and fallow deer densities on the estate can be considered average-high (Braza et al. 1994), while the cattle density $(0.13 \mathrm{cows} / \mathrm{ha})$ is only about half that of the average in dehesa systems with a lower hunting use (approx. $0.25 \mathrm{cows} / \mathrm{ha}$ ). The rabbit density on the estate during the study year may be regarded as normal in the context of Mediterranean ecosystems (Soriguer 1981).

The spatial patterns of herbivore defecation reveal interesting differences among and within plant communities. These differences are closely linked to land use at small and medium scales (tens and hundreds of meters respectively) by different species, and the behavior of each one. While the spatial patterns of herbivore defecation do not exactly match their spatial use, they are generally considered to be a good approximation of landuse (Neff 1968, Rowland et al. 1984, Wood 1988).

At the plant community scale, there were considerable differences in the amount of dung deposited in the 4 vegetation types by the herbivores, although the reason for this behavior was not common to all 4 animals. With the exception of the red deer, these differences were statistically significant in all herbivores, and even in the red deer they were close to the significance threshold.

Daily activity of the 3 ungulates involves ranging over considerable distances in relation to the size of the patches of the plant communities (a few hundred meters). Differences among them in the amount of dung collected may, therefore, be linked to their daily use patterns (Braza and Alvarez 1987, J.M. de Miguel, unpubl. manuscript). Thus, the different diets and daily land use of these 3 herbivores explains the differences found in the samples: cows and fallow deer are basically grazers, while red deer are mixed feeders with a more balanced diet between grazing and browsing on woody stems (Hofmann 1989). This stronger browsing tendency in red deer and its preference for sheltered areas with a dense shrub cover (Braza and Álvarez 1987) explains the smaller differences among plant communities in the amount of dung of this species found during sampling. Red deer use of wooded pastures was higher than that of the shrubby communities.

Cows and fallow deer lie at the opposite extreme with regard to vegetation preferences. Cows mainly use the open ash and

Table 4. Estimated number of seeds deposited per square meter of plant community in dung of 4 herbivore species during 1 year in a Mediterranean grazing system ${ }^{\mathrm{a}}$.

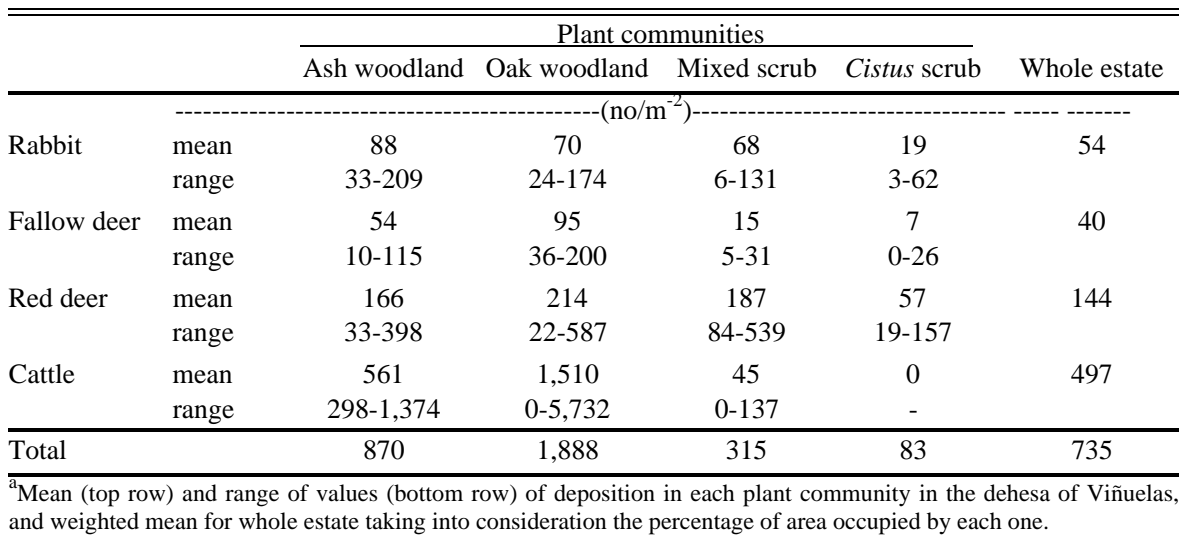




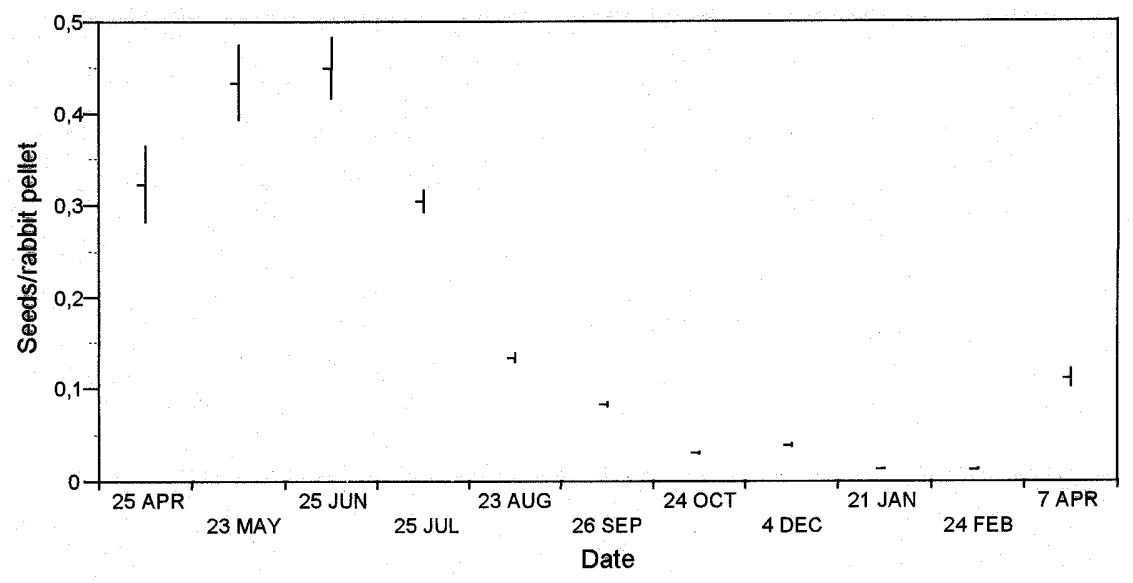

Fig. 2. Seed content (mean \pm standard error) of rabbit pellets along the year. Calculation based on seed content in dung, and weight and number of pellets collected in the 32 subplots on each sampling date.

oak woodlands, make some use of mixed scrub communities and do not feed in Cistus scrub, although they might enter them in winter in search of shelter from the cold. The fallow deer is the species most clearly associated with grasslands, although some of its dung was collected in the mixed and cistus scrub, where it also feeds (Venero 1984, Braza and Álvarez 1987).

In contrast to the ungulates, the territory of the rabbit barely reaches 1 ha (Soriguer 1981, Cowan 1991), and hence the differences in dung densities among areas can be linked to the distinct rabbit densities in the 4 environments. Thus, rabbit density appeared to be highest in the ash woodlands, followed by mixed scrub, oak woodlands and Cistus scrub. This result is linked to the abundance of food and shelter in each plant community (Venero 1984, Soriguer 1988). Cistus scrub provides good shelter but has little grass; mixed scrub also has a good woody cover but an intermediate amount of grass, and wooded pastures provide the highest amount of food and the least shelter.

At a smaller spatial scale, the herbivore defecation patterns in each plant community in the course of the year indicated the animals' spatial selection, which depended on their size. The smallest animals perceive and use different points of each plant community (like a coarse-grained landscape), while the larger herbivores use the land more homogeneously, like finegrained landscapes.Thus, in the 4 plant communities, rabbits consistently defecate more in certain $1 \times 1 \mathrm{~m}$ plots throughout the annual cycle, in correspondence with their smaller size and familiar habit of overwhelmingly defecating at certain points (Wood 1988, Gibb 1993).
In the 3 ungulates, differences among plots were maintained throughout the year in the ash and oak woodlands for the fallow deer, only in the oak woodlands for the red deer, and in none of the plant communities for the cows. These differences, which can be linked to body size (fallow deer: $35-70 \mathrm{~kg}$; red deer: $45-120 \mathrm{~kg}$; cow: $500-600 \mathrm{~kg}$ ) match the priority use of certain areas of passage or rest by fallow deer in the pastures, the more mobile nature of red deer within and among adjacent plant

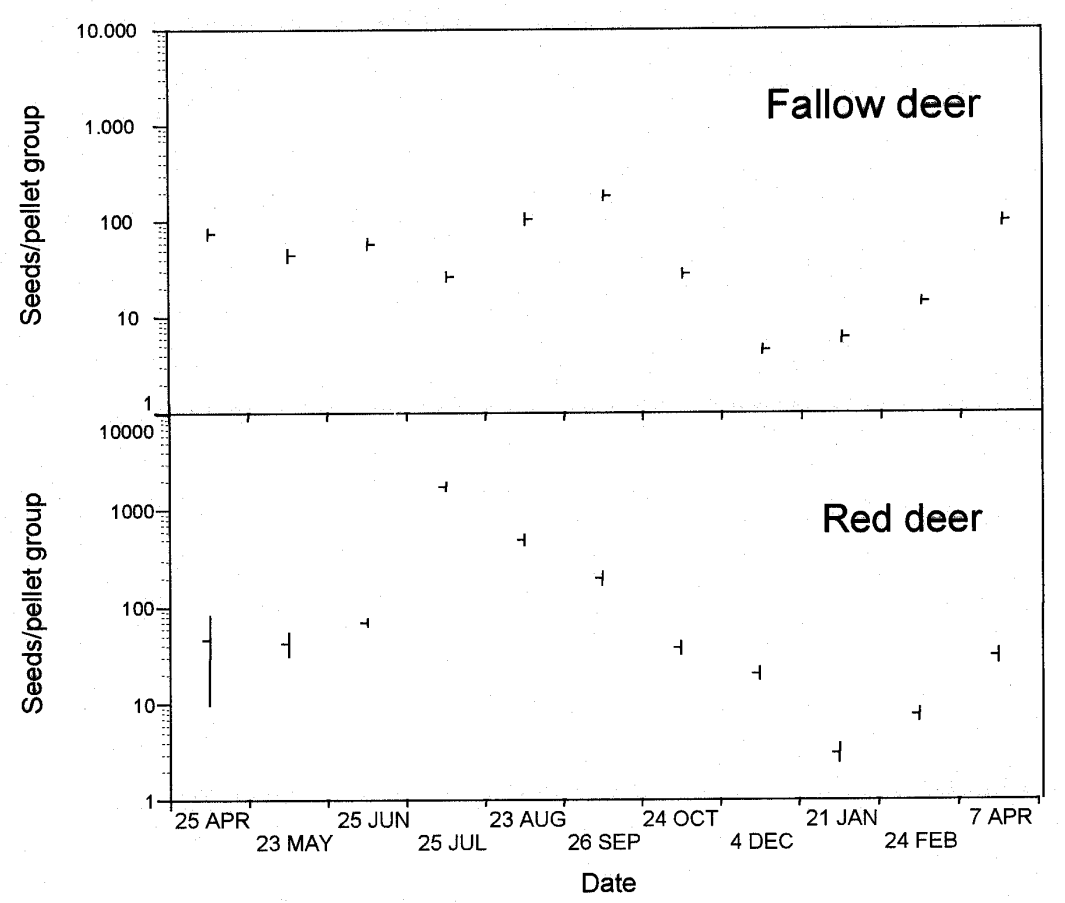

Fig. 3. Number of seeds (mean \pm standard error) deposited in each fallow and red deer defecation throughout the year. Calculation based on dung seed content, and weight and number of pellet groups collected in all 32 plots on each date. Note logarithmic scale of $Y$ axis. 


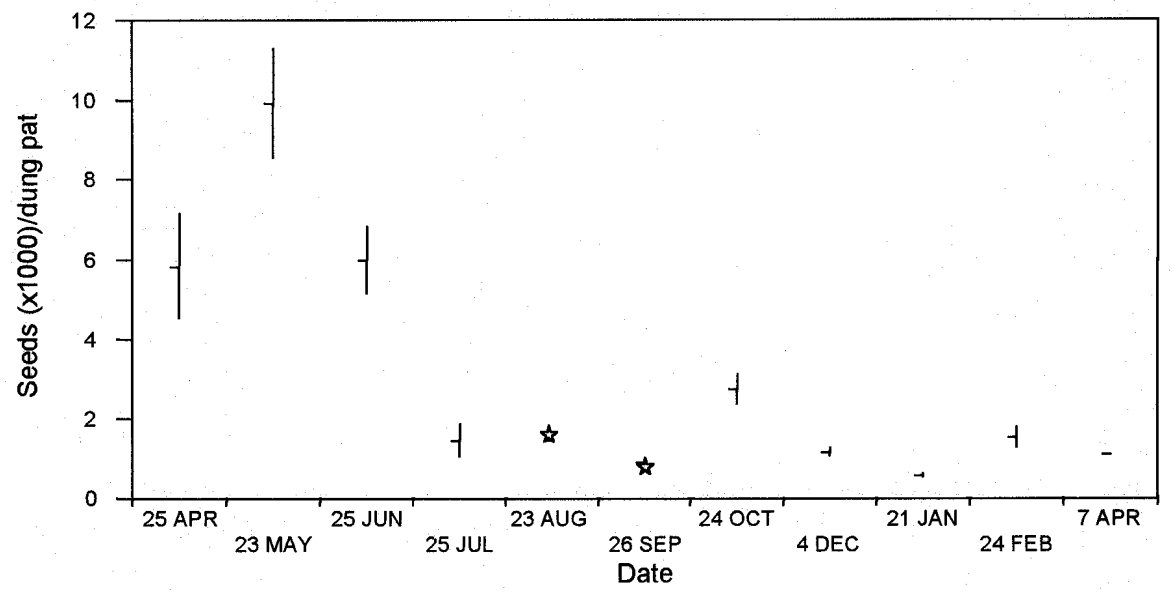

Fig. 4. Number of seeds (mean \pm standard error) deposited within an average-sized $\left(600 \mathrm{~cm}^{2}\right)$ cow pat. Calculation based on (i) dung seed content, (ii) density of cow dung and (iii) mean depth of cow pats measured in all 32 plots on each date. As no cow pats were counted in the sampling plots on 23-VIII or 26-IX, data for these dates (marked with stars) were calculated using mean depth of all pats measured during the study.

its dung in winter and spring (Malo and Suárez 1994), and Juncus bufonius L. Cow and rabbit dung contain seeds from a large number of herbaceous species, particularly Poa annua L., Cerastium glomer atum Thuill. and Biserrula pelecinus in the cow, and Sisymbrium runcinatum Lag. ex DC. and Sagina apetala Ard. in the rabbit.

These temporal patterns and the plant species of which seed was disseminated were quite similar to those found in the same area in a 1990 spring-summer sampling campaign (Malo and Suárez 1995b), although inter-annual meteorological differences caused variations in the seed densities and composition. In 1990, a particularly rainy year, seed densities found in dung, with the exception of the red deer, were between 2 and 3 times higher than those of spring-summer 1991-92. This difference was due to the overall decline in the numbers of seed of herbaceous species in dung, countered only by a steep rise in Cistus ladanifer seeds in red deer dung and to a lesser extent in fallow deer dung. The dry 1990-91 and 1991-92 years (369 $\mathrm{mm}$ and $250 \mathrm{~mm}$ rainfall between September and May contrasted to $575 \mathrm{~mm}$ in 1989-90) restricted the growth and fruiting of grasses, which led to a higher consumption of the fruit (and possibly stems) of the predominant shrub species.

Using these data, we estimate an average annual deposition by herbivores of around $735 \mathrm{seeds} / \mathrm{m}^{2}$ for the whole estate, a relatively low amount. The seed banks of Mediterranean grasslands contain $30,000-40,000$ seeds per $\mathrm{m}^{2}$ in normal years, and can surpass 100,000 seeds per $\mathrm{m}^{2}$ in years of high production (Ortega et al. 1997), while woody communities have 800-66,000 seeds/m² (Parker and Kelly 1989). Although some of these seeds are part of the permanent soil bank (Thomson and Grime 1979), the relative importance of endozoochory is still small in overall terms, even in years when there is a higher seed density in dung.

In the study area, most of the endozoochory was done by large animals. Cows were responsible for dispersing almost $68 \%$ of the seeds, followed by red deer $(20 \%)$, rabbits $(7 \%)$, and fallow deer $(5 \%)$. Although these percentages may show interannual variations, cows are obviously the main dispersers in the area due to the large amount of dung they deposit and its high seed content. In contrast, rabbits disperse a relatively small number of seeds despite the fact that they deposit the largest amount of dung in the area, along with cows. The number of seeds disseminated by rabbits may actually be even lower than our findings: in the scrub zones, rabbit have a mixed diet which includes a certain amount of shrubs (Soriguer 1988), and, thus, the seed content in their dung may be slightly lower in such areas.

The predominantly herbaceous plant communities received the highest seed input via herbivore dung, although in no case was the level comparable to the amount in the soil seed banks. Parallel to the differences among plant communities in the volume of dung deposited, the number of seeds deposited varied by more than an order of magnitude. Thus, Cistus and mixed scrub only received 83 seeds $/ \mathrm{m}^{2}$ and 315 seeds $/ \mathrm{m}^{2}$ respectively, in contrast to 870 seeds $/ \mathrm{m}^{2}$ in ash woodlands and 1,888 seeds $/ \mathrm{m}^{2}$ in the oak woodlands.

However, at small spatial scales, seed deposition along with herbivore dung can have important effects on seed banks and vegetation. Given that the sustainable stocking density in a grazing system such as the study area is relatively low, the dung density on the ground is somewhat limited and its direct effect on vegetation, therefore, moderate. However, the areas which are covered by herbivore dung receive a substantial density of seeds. Practically any defecation by a herbivore contains some seeds, the number deposited in a single spring-summer defecation potentially being hundreds in the case of fallow deer, more than 1,000 in red deer, and close to 10,000 in the case of cattle.

The effect of this seed input to the vegetation ranges from the localized introduction of species to the creation of gradients associated with grazing. On the one hand, the possibility that herbivores might cause the local introduction of species whose seeds are dispersed in dung has been proved (Malo and Suárez 1994, Ocumpaugh et al. 1996), and is also postulated as being the most important effect of herbivore endozoochory (Gardener 1993, Zedler and Black 1992, Sevilla et al. 1996). Species introduction may also occur with woody plants, leading to the invasion of pastures by scrub (Miller and Coe 1993, Peinetti et al. 1993, Malo and Suárez 1998).

On the other hand, herbivore endozoochory can also change the interspecific competitive balance among plants, favouring those which are disseminated via dung. In the grasslands similar to the study area, the vegetation growing in areas occupied by cow pats has been found to be determined by the dung seed content (Malo and Suárez 1995a). Cow pats act as local disturbances which eliminate the predominant perennial grass (Poa bulbosa L.) and introduce annual species, which grow in the gap caused by the cow pat. Given enough time, they are displaced by the Poa bulbosa recolonisation, which takes more than 4 years to regain its cover (Malo and Suárez 1996). A less dramatic but similar process probably takes place with dung pellets, where hundreds of seeds in deer pellets, and even the isolated seeds in rabbit dung, are able to find a place to germinate. However, the high germination rates in dung can also lead to high mortality rates due to competition (Sevilla et al. 1996). 
Finally, the irregular spatial defecation patterns of herbivores complicates this panorama, and probably leads to vegetation mosaics associated with the different input of nutrients and seeds via dung. The different feeding and defecation habits of herbivores thus help to increase plant diversity at different scales in extensive grazing systems such as the Iberian dehesas.

\section{Literature Cited}

Aschmann, H. 1973. Man's impact on the several regions with Mediterranean climates. $\mathrm{p}$. 11-19. In: F. di Castri and H.A. Mooney (Eds.). Mediterranean type ecosystems. Origins and structure, Springer, Berlin.

Braza, F. and F. Álvarez. 1987. Habitat use by red deer and fallow deer in Doñana National Park. Miscellanea Zoologica 11:363-367.

Braza, F., Soriguer, R.C., San José, C., Delibes, J.R., Fandós, P., and L. León. 1994. Métodos para el estudio y manejo de cérvidos. Consejería de Agricultura y Pesca, Junta de Andalucía, Cádiz.

Collins, S.L. and G.E. Uno. 1985. Seed predation, seed dispersal, and disturbance in grasslands: a comment. Amer. Nat. 125:866-872.

Courtney. A.D. 1973. Wild oats and animal feedstuffs. Agric. North. Irel. 47:389-390.

Cowan, D.P. 1991. The availability of burrows in relation to dispersal in the wild rabbit (Oryctolagus cuniculus). Symposium of the Zool. Soc. of London 63:213-230.

Gardener, C.J. 1993. The colonization of a tropical grassland by Stylosanthes from seed transported in cattle faeces. Aust. J. Agr. Res. 44:299-315.

Gardener, C.J., J.G. McIvor, and A. Jansen. 1993. Passage of legume and grass seeds through the digestive tract of cattle and their survival in faeces. J. Appl. Ecol. 30:63-74.

Georgiadis, N.J. and S.J. McNaughton. 1990. Elemental and fibre contents of savannah grasses: variation with grazing, soil type, season and species. J. Appl. Ecol. 27:623-634.

Gibb, J.A. 1993. Sociability, time and space in a sparse population of rabbits (Oryctolagus cuniculus). J. of Zool., London 229:581-607.

Gibb, J.A. and J.M. Williams. 1994. The rabbit in New Zealand. p. 158-204. In: H.V. Thomson and C.M. King (eds), The European rabbit. The history and biology of a successful colonizer, Oxford Univ. Press, Oxford.

Hofmann, R.R. 1989. Evolutionary steps of ecophysiological adaptation and diversification of runminants: a comparative view of their digestive system. Oecologia 78:443-457.

Janzen D.H. 1984. Dispersal of small seeds by big herbivores: foliage is the fruit. Amer. Nat. 123:338-353.

Jones, R.M., M. Noguchi, and B.G. Bunch. 1991. Levels of germinable seed in topsoil and cattle faeces in legume-grass and nitrogen-fertilized pastures in South-East Queensland. Aust. J. Agr. Res. 42:953-968.
Kie, J.G. and B.B. Boroski. 1996. Cattle dis tribution, habitats, and diets in the Sierra Nevada of California. J. Range Manage. 49:482-488.

Malo, J.E. and F. Suárez. 1994. Dispersión endozoócora por el gamo (Dama dama) e introducción de especies con el pastoreo. Pastos 24:47-56.

Malo, J.E. and F. Suárez. 1995a. Establishment of pasture species on cattle dung. The role of endozoochorous seeds. J. Veg. Sci. 6:169-174.

Malo, J.E. and F. Suárez. 1995b. Herbivorous mammals as seed dispersers in a Mediterranean dehesa. Oecologia 104:246-255.

Malo, J.E. and F. Suárez. 1995c. Cattle dung and the fate of Biserrula pelecinus L. (Leguminosae) in a Mediterranean pasture: seed dispersal, germination and recruitment. Bot. J. Linn. Soc. 118:139-148.

Malo, J.E. and F. Suárez. 1996. Las boñigas de vaca, el encespedado de Poa bulbosa y la diversidad de un pastizal de dehesa. Pastos 16:61-75.

Malo, J.E. and F. Suárez. 1998. The dispersal of a dry-fruited shrub by red deer in a Mediterranean ecosystem. Ecography 21:204-211

McNaughton, S.J. 1984. Grazing lawns: animal in herds, plant form and coevolution. Amer. Nat. 124:863-886.

Miller, M.F. and M. Coe. 1993. Is it advantageous for Acacia seeds to be eaten by ungulates? Oikos 66:364-368.

Myers, K., I. Parer, D. Wood, and B.D. Cooke. 1994. The rabbit in Australia. p. 108157. In: H.V. Thomson and C.M. King (eds), The European rabbit. The history and biology of a successful colonizer, Oxford Univ. Press, Oxford.

Neff, D.J. 1968. The pellet-group count technique for big game trend, census, and distribution: A review. J. of Wildl. Manage. 32:597-614.

Ocumpaugh, W.R., S. Archer, and J.W. Stuth. 1996. Switchgrass recruitment from broadcast seed vs. seed fed to cattle. J. Range Manage. 49 :368-371.

Ortega, M., C. Levassor, and B. Peco. 1997. Seasonal dynamics of Mediterranean pasture seed banks along environmental gradients. J. Biogeogr. 24:177-195.

Parker, V.T. and V.R. Kelly. 1989. Seed banks in California chaparral and other Mediterranean climate shrublands. p. 231255. in: M.A. Leck, V.T. Parker and R.L. Simpson (eds.) Ecology of soil seed banks, Academic Press Inc., San Diego, Calif.

Peinetti, R., M. Pereyra, A. Kin, and A. Sosa. 1993. Effects of cattle ingestion on viability and germination rate of calden (Prosopis caldenia) seeds. J. Range Manage. 46:483-486.

Putman, R.J., A.D. Fowler, and S. Tout. 1991. Patterns of use of ancient grassland by cattle and horses and effects on vegetational composition and structure. Biol. Conserv. 56 :329-347.
Rice, W.R. 1989. Analyzing tables of statistical tests. Evolution 43:223-225.

Rogers, P.M., C.P. Arthur, and C.R. Soriguer. 1994. The rabbit in continental Europe. p. 22-63. In: H.V. Thomson and C.M. King (eds), The European rabbit. The history and biology of a successful colonizer, Oxford University Press, Oxford.

Rowland, M.M., G.C. White, and E. M. Karlen. 1984. Use of pellet-group plots to measure trends in deer and elk populations. Wildl. Soc. Bull. 12:147-155.

Russi, L., P.S. Cocks, and E.H. Roberts. 1992. The fate of legume seeds eaten by sheep from a Mediterranean grassland. J. Appl. Ecol. 29:772-778.

Sevilla, G.H., O.N. Fernández, D.P. Minon, and L. Montes. 1996. Emergence and seedling survival of Lotus tenuis in Festuca arundinacea pastures. J. Range Manage. 49:509-511.

Seaman, J.W., S.C. Walls, S.E. Wise, and R.G. Jaeger. 1994. Caveat emptor: rank transform methods and interaction. TREE 9:261-263

Soriguer, R.C. 1981. Biología y dinámica de una población de conejos (Oryctolagus cuniculus) en Andalucía Occidental. Doñana, Acta Vertebrata 8-3:1-379.

Soriguer, R.C. 1988. Alimentación del conejo (Oryctolagus cuniculus L. 1758) en Doñana. SO, España. Doñana, Acta Vertebrata 15:141-150.

Thompson, K. and J.P. Grime. 1979. Seasonal variation in the seed banks of herbaceous species in ten contrasting habitats. J. Ecol. 67:893-921.

Venero, J.L. 1984. Dieta de los grandes fitófagos silvestres del Parque Nacional de Doñana, España. Doñana, Acta Vertebrata 11-3:1-130.

Welch, D. 1985. Studies in the grazing of heather moorland in North-East Scotland. IV. Seed dispersal and plant establishment in dung. J. Appl. Ecol. 22:461-472.

Wood, D.H. 1988. Estimating rabbit density by counting dung pellets. Aus. J. Wildl. Res. 15:665-671.

Yamada, T. and T. Kawaguchi. 1972. Dissemination of pasture plants by livestoock. II. Recovery, viability, and emergence of some pasture plant seeds passed through digestive track of dairy cows. J. Jpn. Grassl. Sci. 18:8-15.

Zedler, P.H. and C. Black. 1992. Seed dispersal by a generalized herbivore: rabbits as dispersal vectors in a semiarid California vernal pool landscape. Amer. Midland Nat. 128:1-10. 